\title{
SENYAWA BIOAKTIF DAUN KUMIS KUCING (Orthosiphon stamineus)
}

\author{
Surahmaida Surahmaida" ${ }^{*}$, Umarudin Umarudin ${ }^{1}$, Junairiah Junairiah ${ }^{2}$ \\ ${ }^{1}$ DIII Farmasi, Akademi Farmasi Surabaya \\ ${ }^{2}$ Departemen Biologi, Fakultas Sains dan Teknologi, Universitas Airlangga \\ "email: fahida1619@gmail.com
}

Received 09 May 2019

Accepted 28 June 2019

\begin{abstract}
Abstrak
Daun kumis kucing (Orthosiphon stamineus) umumnya digunakan sebagai tanaman obat keluarga, hal ini diduga karena senyawa bioaktif yang terkandung didalamnya. Tujuan penelitian ini untuk mengetahui senyawa bioaktif ekstrak n-heksana dan metanol daun kumis kucing (Orthosiphon stamineus) menggunakan Gas Chromatography Mass Spectrometry (GCMS). Tahapan dari metode penelitian ini yaitu proses pencucian dan pengeringan daun kumis kucing, ekstraksi dengan metode maserasi menggunakan pelarut n-heksana dan metanol, serta pengujian senyawa bioaktif menggunakan GCMS. Hasil analisa spektrum GCMS menunjukkan senyawa-senyawa bioaktif yang memiliki aktivitas biologi dan farmakologis yang penting. Keberadaan berbagai senyawa bioaktif pada daun kumis kucing ini menegaskan bahwa tanaman ini dapat digunakan untuk aplikasi farmasi atau bidang ilmu yang lain.
\end{abstract}

Katakunci: Orthosiphon stamineus, senyawa bioaktif, GCMS

\begin{abstract}
The leaves of cat whiskers (Orthosiphon stamineus) are generally used as family medicinal plants, this is thought to be due to the bioactive compounds contained therein. The purpose of this study was to determine the bioactive compounds of n-hexane and methanol extract in the leaves of cat whiskers (Orthosiphon stamineus) using Gas Chromatography Mass Spectrometry (GCMS). The stages of this research method are the washing and drying process of cat whiskers leaves, extraction using maceration method using n-hexane and methanol solvents, and testing of bioactive compounds using GCMS. GCMS spectrum analysis results show bioactive compounds that have important biological and pharmacological activities. The presence of various bioactive compounds in the leaves of cat whiskers confirms that this plant can be used for pharmaceutical applications or other fields of science.
\end{abstract}

Keywords: Orthosiphon stamineus, bioactive compound, GCMS

\section{Pendahuluan}

Eksplorasi tanaman obat saat ini mulai gencar dilakukan karena kandungan senyawa bioaktif di dalamnya. Pengetahuan tentang fitokimia dalam tubuh tumbuhan perlu dilakukan untuk memastikan pentingnya penggunaan ethnomedicinal (Milne, 1993). Tanaman obat merupakan dari farmasi alami, diyakini lebih aman dan terbukti dalam mengobati berbagai penyakit (Sharmila et al., 2016; Ashis, 2003).

Di Indonesia, tanaman kumis kucing (Orthosiphon stamineus) dikenal sebagai tanaman obat keluarga. Menurut Hossain (2007), tanaman yang termasuk dari suku Lamiaceae ini banyak digunakan untuk 
mengobati penyakit seperti edema, hepatitis, penyakit kuning, hipertensi, diabetes mellitus, rematik, influenza dan lain-lain.

Penelitian tentang manfaat daun kumis kucing (Orthosiphon stamineus) telah banyak dilakukan, diantaranya Nair, et al. (2014), menunjukkan bahwa ekstrak etil asetat daun kumis kucing mampu menghambat bakteri patogen (Peudomonas aeruginosa, Aeromonas hydrophilla, Staphylococcus aureus) dan sel kanker kolon. Yam, et al. (2013), melaporkan bahwa ekstrak metanol daun kumis kucing menghasilkan kadar antioksidan yang tinggi dan tidak bersifat toksik. Penelitian oleh Maheswari, et al. (2008) menunjukkan ekstrak metanol daun kumis kucing $(200 \mathrm{mg} / \mathrm{kg})$ memiliki aktivitas hepatoprotektif yang diujikan pada tikus. Selain itu, Prayoga (2008) membuktikan ekstrak etanol daun kumis kucing memiliki efek antiinflamasi pada tikus putih jantan galur Wistar sebesar $64,120 \%$ (dosis $490 \mathrm{mg} / \mathrm{kg} \mathrm{BB}$ ).

Dari uraian di atas, diketahui bahwa belum ada penelitian yang mengidentifikasi senyawa bioaktif daun kumis kucing dengan pelarut n-heksana dan metanol. Padahal, kandungan senyawa bioaktif yang terdapat pada tanaman obat menginterpretasikan aktivitas biologis dan farmakologis yang perlu kita ketahui, khususnya pada daun kumis kucing (Orthosiphon stamineus).

Oleh sebab itu, penelitian ini bertujuan untuk mengidentifikasi senyawa-senyawa bioaktif yang terdapat ekstrak n-heksana dan metanol daun kumis kucing (Orthosiphon stamineus) menggunakan Gas Chromatography Mass Spectrometry (GCMS) untuk dianalisis aktivitas biologis dan farmakologisnya.

\section{Metode Penelitian}

Alat dan bahan

Alat yang digunakan dalam penelitian ini adalah toples kaca, timbangan analitik, beker glas, corong, ayakan dan GCMS. Bahan penelitian ini antara lain n-heksana, metanol, aluminium foil, kertas saring dan daun kumis kucing (Orthosiphon stamineus) yang diperoleh dari daerah Juanda Sidoarjo.

\section{Proses Ekstraksi}

Tanaman kumis kucing diperoleh di daerah Juanda Sidoarjo. Tanaman tersebut dideterminasikan di Layanan Unit Biologi Universitas Airlangga untuk memastikan bahwa tanaman tersebut benar-benar tanaman yang akan diujikan. Hasil determinasi menunjukkan bahwa tanaman tersebut adalah tanaman kumis kucing (Orthosiphon stamineus). Bagian tanaman kumis kucing yang digunakan pada penelitian ini adalah bagian daunnya. Satu kilogram daun kumis kucing dicuci bersih dengan air mengalir untuk menghilangkan kotoran yang menempel lalu dikeringanginkan. Sampel kering daun kumis kucing dihaluskan dengan blender hingga menjadi serbuk halus. Proses ekstraksi dilakukan dengan metode maserasi, yaitu merendam 20 gram serbuk halus daun kumis kucing ke dalam toples kaca yang berisi $600 \mathrm{ml}$ pelarut n-heksana selama selama 3 hari. Perlakuan yang sama untuk proses maserasi daun kumis kucing dengan pelarut metanol. Filtrat dari masingmasing ekstrak daun kumis kucing diambil $50 \mathrm{ml}$ untuk identifikasi senyawa menggunakan GCMS.

Proses Identifikasi Senyawa Bioaktif Ekstrak n-Heksana Daun Kumis Kucing

Alat GCMS digunakan untuk mengidentifikasi senyawa bioaktif daun kumis kucing. GCMS yang digunakan yaitu Agilent 6980N Network GC System yang dilengkapi dengan kolom kapiler HP5 MS dengan ukuran $0,25 \mathrm{~mm} \times 30 \mathrm{~m} \times$ $0,25 \mu \mathrm{m}$. dan kromatografi gas dihubungkan ke Mass Selective Detektor (MS-DSQ-II) dengan perangkat lunak XCALIBUR. Untuk deteksi GCMS, sistem ionisasi elektron dengan energi ionisasi $-70 \mathrm{eV}$ digunakan. gas helium digunakan sebagai gas pembawa pada laju aliran konstan $1 \mathrm{ml} / \mathrm{menit}$ dan volume 
sampel yang disuntikkan adalah $2 \mu \mathrm{l}$; suhu injektor $250^{\circ} \mathrm{C}$; suhu sumber ion $230^{\circ} \mathrm{C}$. Oven suhu diprogram dari $50^{\circ} \mathrm{C}$ hingga $280^{\circ} \mathrm{C}$ pada laju $10^{\circ} \mathrm{C} /$ menit dan isotermal selama 1 menit. Persentase relatif dari masing-masing konstituen ekstrak dinyatakan sebagai persentase dengan normalisasi area puncak, dan identifikasi senyawa bioaktif menggunakan pustaka Willey versi 7.0. Proses pengujian GCMS sesuai dengan prosedur Kannan, et al. (2016).

\section{Hasil dan Pembahasan}

Pada penelitian ini, identifikasi senyawa-senyawa bioaktif yang terdapat pada ekstrak $n$-heksana daun kumis kucing menggunakan GCMS. Ada dua keuntungan yang signifikan dalam menganalisis tanaman obat menggunakan GCMS, yaitu; (1) dengan kolom kapiler, GCMS secara umum memiliki kemampuan pemisahan yang sangat baik; (2) dengan spektroskopi massa digabungkan dan database spektral massa yang sesuai (Sermakkani \& Thangapandian, 2012).

Identifikasi senyawa bioaktif daun kumis kucing dilakukan dengan membandingkan pola spektrum massa dengan pola fragmentasi senyawa referensi. Hasil analisis senyawa bioaktif ekstrak daun kumis kucing menggunakan pustaka GCMS Wiley versi 7.0.

Tabel 1. Senyawa bioaktif ekstrak daun kumis kucing (Orthosiphon stamineus) yang teridentifikasi dengan GCMS

\begin{tabular}{llrr}
\hline \multirow{1}{*}{ Pelarut } & \multicolumn{1}{c}{ Nama Senyawa Bioaktif } & \% Total & RT \\
\hline & 1,1-Dicyclopentylethane & 11,009 & 15,820 \\
& Bicyclo[3.2.0]hept-2,6-diene-1,2,3,4,4,5,6-d(7) & 7,020 & 18,190 \\
& n-Butyl palmitate & 22,516 & 20,290 \\
& 1-oxo03.alpa.-(4-methyl-3-pentenyl)-6.alpa.- & 21,805 & 21,750 \\
n-Heksana & methyl-6a.alpa.-carbomethoxy-1,3,3a.alpa.,6a- & & \\
& tetrahydrocyclopenta[c]furan & & \\
& 1,1,3,3,5,5,7,7,9,9,11,11,13,13- & 15,117 & 28,330 \\
& tetradecamethylheptasiloxane & & \\
& 1,4-bis(trimethylsilyl)-benzene & 6,502 & 28,530 \\
& Silicone grease, Siliconfett & 16,031 & 28,810 \\
\hline Z,Z-6,24-Tritriacontadien-2-one & 5,640 & 17,429 \\
& Phytol & 16,198 & 20,042 \\
& .alpha.trans-sesquicyclogeraniol & 5,230 & 25,445 \\
& D,.alpha.-Tocopherol & 14,785 & 27,470 \\
& (E)-5,10-secocholest-1(10)-en-3,5-dione & 10,355 & 28,005 \\
Stigmasta-5,22-dien-3.ol & 18,612 & 28,196 \\
Metanol & 21,710 & 28,578 \\
& 1,5-Dimethyl-6-(1,5-dimethylhexyl)-15,16-epoxy- & & \\
& 18-oxatetracyclo[9.6.1.0(2,10).0(5,9)]octdecane-13- & & \\
& one & 7,470 & 29,037 \\
\hline Silicon grease, siliconfett & &
\end{tabular}


Tabel 1 menunjukkan 2 senyawa bioaktif terbesar pada ekstrak n-heksana daun kumis kucing yaitu n-Butyl palmitate $(22,516 \%)$ dan 1-oxo03.alpa.-(4-methyl3-pentenyl)-6.alpa.-methyl-6a.alpa. -carbo methoxy- 1,3,3 a.alpa., 6a- tetrahydrocyclo penta[c]furan $(21,085 \%)$. Kedua senyawa tersebut termasuk ke dalam golongan senyawa ester.

Sedangkan pada ekstrak metanol daun kumis kucing mengandung senyawa bioaktif 1,5-Dimethyl -6- (1,5-dimethyl hexyl)-15,16-epoxy-18-oxatetracyclo[9.6.
1.0(2,10).0(5,9)] octdecane - 13 - one $(21,710 \%)$ dan Stigmasta-5,22-dien-3.ol $(18,612 \%)$ yang termasuk ke dalam golongan senyawa steroid.

Senyawa-senyawa bioaktif yang teridentifikasi dengan GCMS kemudian dianalisis aktivitas biologis maupun farmakologisnya seperti pada Tabel 2 untuk senyawa bioaktif ekstrak n-heksana dan Tabel 3 untuk senyawa bioaktif ekstrak metanol.

Tabel 2. Aktivitas biologis dari senyawa bioaktif ekstrak n-heksana daun kumis kucing (Orthosiphon stamineus)

\section{Senyawa Bioaktif}

1,1-Dicyclopentylethane

Bicyclo[3.2.0]hept-2,6-diene$1,2,3,4,4,5,6-\mathrm{d}(7)$

n-Butyl palmitate

1-oxo03.alpa.-(4-methyl-3pentenyl)-6.alpa.-methyl-6a.alpa.carbomethoxy-1,3,3a.alpa.,6atetrahydrocyclopenta[c]furan

\section{$1,1,3,3,5,5,7,7,9,9,11,11,13,13-$} tetradecamethylheptasiloxane 1,4-bis(trimethylsilyl)-benzene Silicone grease, Siliconfett

\section{Aktivitas Biologis}

Antiinfluenza A dan B (Smee et al., 2001), antitumor dan antimikroba (Kakiuchi et al., 1986) Antimikroba, antinosiseptif, antioksidan, insektisida (Dembitsky, 2008)

Penolak serangga (repellent), antitumor (Harada et al., 2002), bahan pelembut atau pelarut dalam industri kosmetik (parfum) (Khan et al., 2016), antioksidan, plasticizer, flavours atau perisa (Bouaziz et al., 2010; Syamsul et al., 2010; Radzi et al., 2005)

Antijamur dan antibakteri, antiinflamasi, analgesik, antituberkular, anti depresi, antivirus, antikanker antileishmanial (Shalini et al., 2010), katalis dalam industri (Doung et al., 2004), bahan matriks semikonduktor organik (Hartman et al., 2010)

Antibakteri, antijamur, kosmetik, cat, pernish (Febronia \& Santhi, 2017)

Antitumor (Prakasia \& Nair, 2015)

Agen antiinflamasi (Mane et al., 2010), anestesi lokal (Kossakowski \& Zawadowski, 1987), sitotoksik terhadap sel kanker (Kossakowski et al., 2005), bahan baku di industri barang pecah belah (Haiduc, 2004) 
Tabel 3. Aktivitas biologis dari senyawa bioaktif ekstrak metanol daun kumis kucing (Orthosiphon stamineus)

\begin{tabular}{|c|c|}
\hline Senyawa Bioaktif & Aktivitas Biologis \\
\hline Z,Z-6,24-Tritriacontadien-2-one & $\begin{array}{l}\text { Antioksidan, antibakteri, immunomodulator (Amin, } \\
\text { 2015), biodegradasi limbah, stimulus pertumbuhan } \\
\text { (Pimda \& Bunnag, 2017) }\end{array}$ \\
\hline Phytol & $\begin{array}{l}\text { Prekursor vitamin E, antimikroba, antikanker (Byju } \\
\text { et al., 2013), antisedatif, ansiolitik (Rivelilson et al., } \\
\text { 2014), sitotoksik, antioksidan, antinosiseptif, } \\
\text { antiinflamasi, antibodi, dan antimikroba (Islam et } \\
\text { al., 2018) }\end{array}$ \\
\hline .alpha.trans-sesquicyclogeraniol & $\begin{array}{l}\text { Antioviposisi pada serangga (Muryati et al., 2012), } \\
\text { antibakteri, antiflogistik/ antiperadangan, } \\
\text { antituberkulosis (Salimpour et al., 2011) }\end{array}$ \\
\hline D,.alpha.-Tocopherol & Antioksidan (Astley, 2003) \\
\hline $\begin{array}{l}\text { (E)-5,10-secocholest-1(10)-en- } \\
\text { 3,5-dione }\end{array}$ & Antilipemik (Jaafar \& Jaafar, 2019) \\
\hline Stigmasta-5,22-dien-3.ol & $\begin{array}{l}\text { Sintesis progesteron, antimikroba, antivirus, } \\
\text { antikanker, antioksidan (Sunita et al., 2017) }\end{array}$ \\
\hline $\begin{array}{l}\text { 1,5-Dimethyl-6-(1,5- } \\
\text { dimethylhexyl)-15,16-epoxy-18- } \\
\text { oxatetracyclo[9.6.1.0(2,10).0(5,9) } \\
\text { ]octdecane-13-one }\end{array}$ & Antimikroba (Pradheesh et al., 2017) \\
\hline Silicon grease, siliconfett & $\begin{array}{l}\text { Agen antiinflamasi (Mane et al., 2010), anestesi } \\
\text { lokal (Kossakowski \& Zawadowski, 1987), } \\
\text { sitotoksik terhadap sel kanker (Kossakowski et al., } \\
\text { 2005), bahan baku di industri barang pecah belah } \\
\text { (Haiduc, 2004) }\end{array}$ \\
\hline
\end{tabular}

Hasil analisis spektrum GCMS menunjukkan senyawa bioaktif yang teridentifikasi baik pada ekstrak n-heksana maupun ekstrak metanol dari daun kumis kucing (Orthosiphon stamineus) mengandung Silicone grease, Siliconfett. Senyawa bioaktif Silicone grease, Siliconfett termasuk polimer dimetilsiloksana $\left(\mathrm{Me}_{2} \mathrm{SiO}\right) \mathrm{x}$. Silicone grease, Siliconfett adalah katalis yang kuat dalam polimerisasi gas diazomethane untuk menghasilkan polymethylene (Haiduc, 2004).

Senyawa bioaktif yang teridentifikasi dari ekstrak n-heksana dan ekstrak metanol daun kumis kucing memiliki banyak aktivitas biologis dan farmakologis. Hasil penelitian ini diharapkan bermanfaat bagi peneliti lain dan dapat ditindaklanjuti untuk penelitian selanjutnya dan pengembangan dari senyawa tersebut dapat diaplikasikan di bidang ilmu lain.

\section{Kesimpulan}

Senyawa bioaktif yang berhasil diidentifikasi dengan GCMS pada daun kumis kucing (Orthosiphon stamineus) yang dimaserasi dengan pelarut n-heksana adalah 1,1-Dicyclopentylethane; Bicyclo [3.2.0]hept-2,6-diene -1,2,3,4,4,5,6-d(7); n-Butyl palmitate; 1-oxo03.alpa. -(4methyl-3-pentenyl)-6.alpa. - methyl -6a. 
alpa. -carbomethoxy-1,3,3a.alpa., 6a-tetra hydrocyclopenta[c]furan; $1,1,3,3,5,5,7,7,9$, 9,11,11,13,13- tetradecamethylhepta siloxane; 1,4 - bis(trimethylsilyl) -benzene dan Silicone grease, Siliconfett. Ekstrak metanol daun kumis kucing mengandung Z,Z-6,24-Tritriacontadien-2-one; Phytol; .alpha.trans-sesquicyclogeraniol; D,.alpha. -Tocopherol; (E)-5,10-secocholest-1(10)en-3,5-dione; Stigmasta - 5,22 - dien-3.ol; 1,5-Dimethyl-6 -(1,5-dimethylhexyl)-15,

\section{Daftar Pustaka}

Amin, M.A.A., 2015, Medicinal compound extraction from the whole body of Cynodon dactylon (L.) Pers by using green solvents, Disertasi, Bandar Seri Iskandar: Universiti Teknologi Petronas.

Ashis, G., 2003, Herbal folk remedies of Bankura and Medinipur districts, West Bengal, Indian Journal of Traditional Knowledge, 2(4), 393396.

Astley, S.B., 2003, Antioxidants: Role of Antioxidant Nutrients in Defense Systems. Encyclopedia of Food Science and Nutrition, $2^{\text {nd }}$ Edition, Academic Press, 282-289.

Bouaziz, A., Horchani, H., Salem, N.B., Chaari, A., Chaabouni, M., Gargouri, Y., Sayari, A, 2010, Enzymatic propyl gallate synthesis in solvent-free system: optimization by response surface methodology, $J$ Mol Catal B: Enzym, 7, 242 - 250.

Byju, K., Vasundhara, G., Anuradha, V., Nair, S.M., Kumar, N.C, 2013, Presence of Phytol, a Precursor of Vitamin E in Chaetomorpha antinnina, Mapana J Sci, 12(2), 5765.

Dembitsky, V.M, 2008, Bioactive cyclobutane-containing alkaloids. $J$ Nat Med, 62, 1-33.

Doung, H.A., Cross, M.J., Louie, J., 2004, $\mathrm{N}-$ Heterocyclic carbenes as highly efficient catalysts for the 16-epoxy-18 -oxatetracyclo[9.6.1.0(2,10). $0(5,9)$ ]octdecane-13-one; dan Silicon grease, siliconfett.

\section{Ucapan Terima Kasih}

Penulis mengucapkan terima kasih kepada DRPM Kemenristekdikti yang telah mendanai penelitian ini melalui Hibah Penelitian Dosen Pemula Tahun 2019.

cyclotrimerization of isocyanates, Org. Lett., 6, 4679-4681.

Febronia, B.F. \& Santhi, G., 2017, In Vitro Efficacy of Piper betle Leaf Extract against Rhizoctonia solani Causing Damping off Disease of Chilli, International Journal for Pharmaceutical Research Scholars (IJPRS), 6(1), 109-115.

Haiduc, I., 2004, Silicone Grease: A Serendipitous Reagent for the Synthesis of Exotic Molecular and Supramolecular Compounds, Organometallics, 23, 3-8.

Harada, H., Yamashita, U., Kurihara, H., Fukushi, E., Kawabata, J., Kamei, Y, 2002, Antitumor activity of palmitic acid found as a selective cytotoxic substances in a marine red alga, Anticancer Res, 22(5), 2587-2590.

Hartmann, H., Zeika, O., Ammann, M., Dathe, R, 2010, Imidazole derivatives and their use as dopants for doping an organic semiconductor matrix material. Patent No. US2010/0301277A1.

Hossain, A.M., Salehuddin, S., Ismail, Z., 2007, Isolation and Characterization of a new poly hydroxyl Flavone from the Leaves of Orthosiphon stamineus, Indian J. Nat. Prod., 23(4), 3-7.

Islam, M.T., Ali, E.S., Uddin, S.J., Shaw, S., Islam, M.A., Ahmed, M.I., Chandra, S.M., Kamakar, U.K., Yarla, N.S., Khan, I.N., Billah, 
M.M., Piecynska, M.D., Zenqin, G., Malainer, C., Gulei, D., BerindanNeaqoe, I., Apostolov, A., Banach, M., Yeung, A.W.K., El-Demerdash, A., Xiao, J., Dey, P., Yele, S., Jozwik, A., Strzalkoska, N., Marchewka, J., Rengasamy, K.R.R., Horbanczuk, J., Kamal, M.A., Mubarak, M.S., Mishra, S.K., Shilpi, J.A., Atanasov, A.G., 2018, Phytol: A Review of biomedical activities, Food Chem Toxicol, 121, 82-94.

Jaafar, N.S. \& Jaafar, I.S., 2019, Eruca sativa Linn.: Pharmacognostical And Pharmacological Properties And Pharmaceutical Preparations, Asian Journal Of Pharmaceutical And Clinical Research, 12(3), 39-45.

Kakiuchi, K., Ue, M., Takeda, M., Tadaki, T., Kato, Y., Nagashima, T., Tobe, Y., Koike, H., Ida, N. and Odaira, Y., 1986, Antiproliferating Polyquinanes. V. ${ }^{1)}$ Di- and Triquinanes Involving $\alpha$-Alkalydene Cyclopentanone, Cyclopenenone, and $\gamma$-Lactone Systems, Chem. Pharm. Bull., 35(2), 617-631.

Kannan, M., Muthusamy, P., Venkatachalam, U., 2016, Quantification of bioactive components from medicinal herb Ganoderma lucidum using HPTLC and GC-MS techniques, Research Journal of Biotechnology, 11(6): 4957.

Khan, N.R., Jadhav, S.V., Rathod, V.K., 2016, Enzymatic synthesis of $n$-butyl palmitate in a solvent free system: RSM optimization and kinetic studies, Biocat Biotrans, 34, 99-109.

Kossakowski, J. \& Zawadowski, T., 1987, Synthesis of some amides of benzofurane-2-carboxylic and benzofurane-3-carboxylic acids with potential antidepressant activity, Acta Poloniae Pharmaceutica, 44(6). 497-502.

Kossakowski, J., Ostrowska, K., Hejchman, E., Wolska I., 2005,
Synthesis and structural characterization of derivatives of 2and 3-benzo[b]furan carboxylic acids with potential cytotoxic activity, Farmaco, 60(6-7). 519-527. Maheswari, C., Maryammal, R., Venkatanarayanan, R., 2008, Hepatoprotective Activity of "Orthosiphon stamineus" Damage Caused by Paracetamol in Rats, Jordan Journal of Biological Sciences, 1(3). 105-108.

Mane, B.Y., Agasimundin, Y.S., Shivakumar, B., 2010, Synthesis of benzofuran analogs of fenamates as non steroidal antiinflammatory agents, Indian Journal of Chemistry, 49(2), 264-269.

Milne, A., 1993, Inhalational and local anesthetics reduce tactile and thermal responses in Mimosa pudica Linn, Masui, 1190-1193.

Muryati, Trisyono, Y.A., Witjaksono, Wahyono, 2012, Effects of Citronella Grass Extract on The Oviposition Behavior of Carambola Fruit Fly (Bactrocera carambolae) In mango, ARPN Journal of Ahricultural and Biological Science, 7(9), 672-679.

Nair, A., Kiruthika, D., Dheeba, B., Tilton, F., 2014, Cytotoxic Potentials Of Orthosiphon stamineus Leaf Extracts Against Pathogenic Bacteria And Colon Cancer Cells, Asian Journal of Science and Technology, 5(3), 221-225.

Pimda, W. \& Bunnag, S., 2017, Impact of Inorganic Nutrients and Heavy Metals Present as Co-contaminants on Biodegradation of Petroleum Hydrocarbons by Phormidium ambiguum Strain TISTR 8295, Water Air Soil Pollut, 2017, 228258.

Pradeesh, G., Suresh, J., Suresh, H., Ramani, A., Hong, I., 2017, Antimicrobial Activity And Identification of Potential Compounds From The Chloroform 
Extract Of The Medicinal Plant Cyathea Nilgirensis Holttum, World Journal Of Pharmacy And Pharmaceutical Sciences, 6(7), 1167-1184.

Prakasia, P.P. \& Nair, A.S., 2015, Chemical fingerprint of essential oil components from fresh leaves of Glycosmis pentaphylla (Retz.) Correa, The Pharma Innovation Journal, 3(12), 50-56.

Prayoga, S., 2008, Efek Antiinflamasi Ekstrak Etanol Daun Kumis Kucing (Orthosiphon stamineus Benth.) Pada Tikus Putih Jantan Galur Wistar, Skripsi, Fakultas Farmasi Universitas Muhammadyah Surakarta, Surakarta.

Radzi, S..M., Basri, M., Salleh, A.B., Ariff. A., Mohammad, R., 2005, High performance enzymatic synthesis of oleyloleate using immobilised lipase from Candida antarctica, Electron J Biotechnol, 8, 292-298.

Rivelilson, M.F., Costa, J.P., Oliveira, G.A.L., Almeida, A.A.C., Islam, M.T., Sousa, D.P., 2014, Anxiolyticlike effects of phytol: Possible involvement of GABAergic transmission, Brain Research, 1574, 34-42.

Salimpour, F., Mazooji, A., Darzikolaei, S.A., 2011, Chemotaxonomy of six Salvia species using essential oil composition markers, Journal of Medicinal Plants Research, 5(9), 1795-1805.

Sermakkani, M. \& Thangapandian, 2012, GC-MS Analysis Of Cassia italica Leaf Methanol Extract, Asian Journal of Pharmaceutical and Clinical Research, 5(2), 90-94.

Shalini, K., Sharma, P.K., Kumar, N., 2010, Imidazole and its biological activities: A review, Der Chemica Sinica, 1(3), 36-47.

Sharmila, M., Rajeswari, M., Jayashree, I., Geetha, D.H., 2016, GC-MS Analysis of Bioactive Compounds of
Amaranthus polygonoides Linn. (Amaranthaceae), International Journal of Applied and Advanced Scientific Research (IJAASR), 1(1), 174-180.

Smee, D.F., Huffman, J.H., Morrison, A.C., Barnard, D.L., Sidwell, R.W., 2001, Cyclipentane Neuraminidase Inhibitors With Potent In Vitro AntiInfluenza Virus Activities, Antimicrobial Agents And Chemotherapy, 45(3), 743-748.

Sunita, A., Sonam, M., Ganesh, K., 2017, Gas Chromatography-Mass Spectrophotometry Analysis Of An Endangered Medicinal Plant, Sarcostemma Viminale (L.) R.Br. From Thar Desert, Rajashtan (India), Asian Journal of Pharmaceutical and Clinical Research, 10(9), 210213.

Syamsul, K.M.W., Salina, M.R.S., Siti, S.O., Hanina, M.N., Basyaruddin, M.A.R., Jusoff, K., 2010, Synthesis of lauryl palmitate via lipasecatalyzed reaction, World Appl Sci J, 11, 401-407.

Yam, M.F., Lim, C.P., Ang, L.F., Por, L.Y., Wong, S.T., Asmawi, M.Z., Basir, R., Ahmad, M., 2013, Antioxidant and Toxicity Studies of $50 \%$ Methanolic Extract of Orthosiphon stamineus Benth, Biomed Research International, 2013, 1-10. 